Journal of Procurement \&
Supply Chain

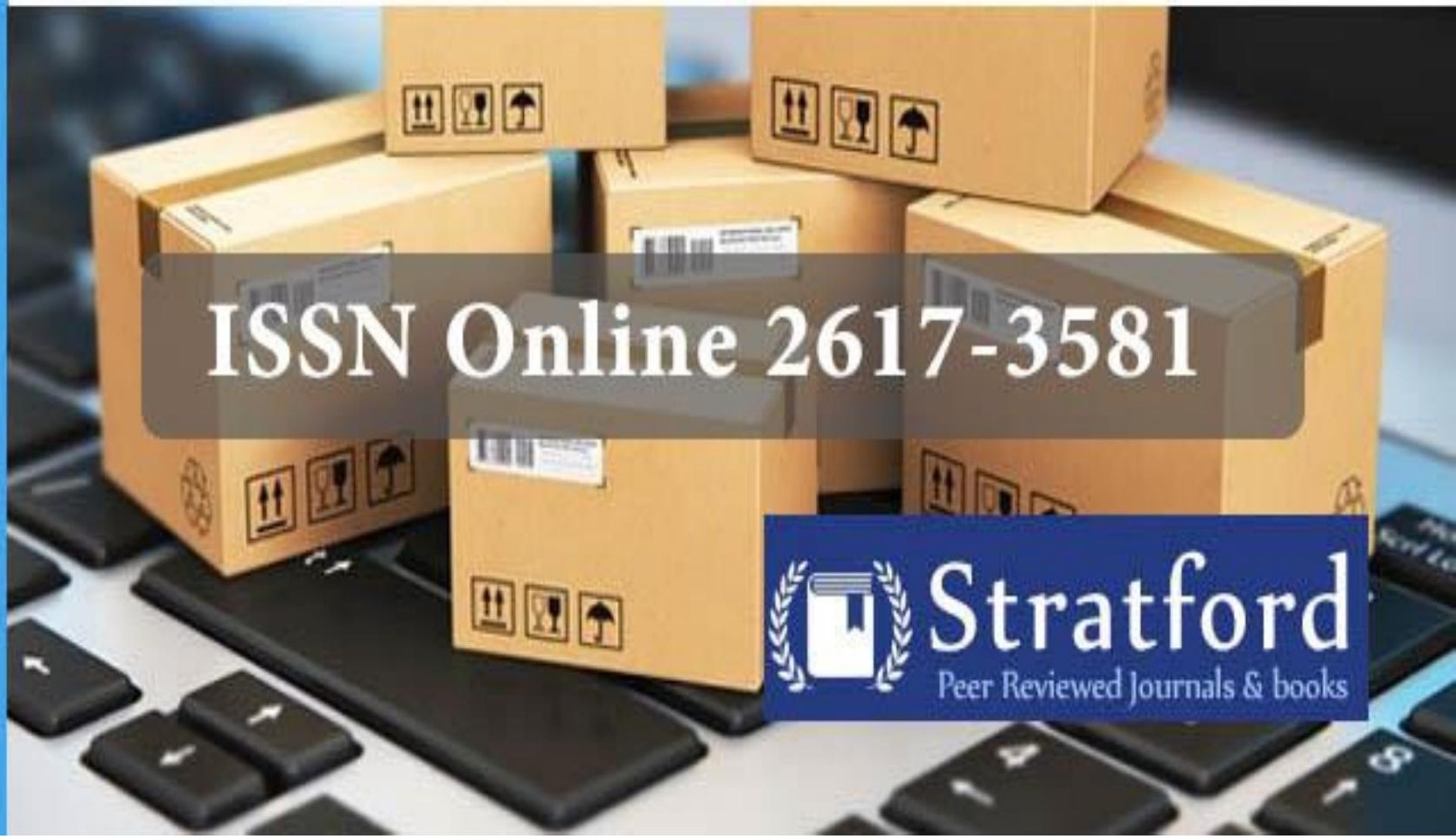

Warehouse Management and Operational Performance of Clearing and Forwarding Companies in Rwanda: A Case of Gorrila Logistics Ltd.

Ruburika Vedaste \& Dr Paul Munene Muiruri PhD

ISSN: 2617-3581 


\title{
Warehouse Management and Operational Performance of Clearing and Forwarding Companies in Rwanda: A Case of Gorrila Logistics Ltd.
}

\author{
${ }^{1 *}$ Ruburika Vedaste $\&^{2}$ Dr. Paul Munene Muiruri, PhD \\ ${ }^{1,2}$ Mount Kenya University of Rwanda, School of Business and Economic, \\ Kigali Rwanda \\ *Corresponding author's email: vedaste1979@gmail.com \\ Co-author email address: Munenepaul1@gmail.com
}

How to cite this article: Vedaste, R. \& Muiruri, P., M. (2021). Warehouse Management and Operational Performance of Clearing and Forwarding Companies in Rwanda: A Case of Gorrila Logistics Ltd. Journal of Procurement and Supply Chain, 5(1), 39-49. https://doi.org/10.53819/81018102t3017

\begin{abstract}
High operational costs and poor customer service that faces most companies can be explained by among other factors poor logistics management. The modern business world coupled with mass competition demands that firms take keen interest on logistics management as it's one of the emerging key determinants of firms' profitability and sustainable growth. This study sought to investigate the effects of warehouse management on operational performance of Clearing and forwarding companies in Rwanda taking Gorrilla logistics ltd as a case study. Specifically, the study focused on the effects of logistics management on operational performance of Clearing and forwarding companies in Rwanda taking Gorrilla Logistics ltd as the case study. The study was based on supply chain theory. The study adopted in this research descriptive research designs. The targeted population was all 240 staff of Gorrilla logistics ltd which where sample size of 150 respondents was calculated using Yamane's formula. Data collected constituted primary data which was collected with the aid of questionnaire and secondary data collected from company documentaries. Analysis of the data utilized both descriptive and inferential statistic was conducted using SPSS Version and findings presented in graphs and tables. The respondents widely agreed that logistics management affect operational performance. The study found that warehouse management affects operational performance of Gorrilla logistics ltd in Rwanda. R squared value of 0.684 implied that the three logistic management practices discussed in this study accounts for $68.4 \%$ variations in operational performance. Correlation analysis findings indicated a strong positive association between warehouse management and operational performance. From the findings the researcher concluded that there is a strong positive significant effect of warehouse management on operational performance of clearing and forwarding companies. The researcher recommended that companies should improve their warehouse management practices in order to achieve operational performance.
\end{abstract}

Keywords: Warehouse Management, Operational Performance, Clearing and Forwarding Companies 


\subsection{Introduction}

Warehouse manipulate might be very crucial for higher popular universal overall performance of the company (Natasha et al., (2017) Warehousing is the garage of products, even as distribution middle precedes a postproduction warehouse for completed devices held for distribution. Therefore, warehousing and distribution facilities essentially have the same characteristic of products and merchandise garage (Coyle at el., 2013).

The warehouse and distribution centres are very crucial nodes in a deliver chain network. They carry out valuable capabilities that guide the motion of materials, storing devices, processing merchandise, de-aggregating automobile loads, growing inventory maintaining unit assortments and assembling shipments (Langevin \& Riopel, 2005). The green manipulate of warehouses facilitates to optimise the prevailing manufacturing and distribution strategies and extensively help with inside the motive of value reduce charge and company enhancement. The current turbulent environment, corporations want to perform at most universal overall performance and offer advanced company to make certain profitability. Three elements has been placed to have an effect on universal overall performance and effectiveness of the warehouse operations with apprehend to speedy moving patron devices business enterprise along with simplicity/complexity of the warehouse manipulate systems, product slotting strategies and format making plans of the warehouse (Lakmal \& Wickramarachchi, 2011). The groups potential to efficiently manipulate the warehouse lessen charges and achievement operations are crucial to their success. It is pertinent to say that the groups face first rate traumatic situations in dealing with warehouses. The characteristic and significance of warehouses in American economic device has been altered to first rate volume because of changes with inside the manner of uncooked materials, intermediate devices, and completed merchandise (John \&Bowen, 2008).

\subsection{Statement of the Problem}

Clearing and forwarding companies plays greatest pillars Logistics in management that in turn contribute to performance of any organization. Currently, business clearing and forwarding world characterized by stiff competition and thirst of efficiency in organizational operations demands improvement in the management of 1 warehouse management practice that conduct the processes of importing or exporting commodities from one country to another on behalf of the importer or exporter. This facilitates the movement of goods and cargo from one country to another. They constitute of clearing agents and freight forwarders (Kaan, 2015).

Rwanda clearing and forwarding companies face a number of warehouse management challenges related to mismanagement and high logistics costs (ADR, 2012). For instance, Gorilla Logistics Limited is the regional market leader in the logistics industry in international parcel, express, air and ocean freight, road and rail transportation, contract logistics and international mail services to customers. It has integrate technology into systems to serve clients with utmost efficiency for customers to check shipment movements themselves in real-time For instance in year 2020 Gorilla logistics cleared 987 air freight,549 ocean freight 68 road freight and 174 cargoes by rail freight and has the company has 49 clients and partner who they work (Gorilla logistics, 2020). 
In addition Rwanda pay RWF 12 per kilogram shipping and shortage of consignment but Gorilla has reduced the rate of RWF 8 per kilogram and payment is done 15days from when the invoice is issued.

Newtimes (2012) reported that congestion is majorly caused by delays in collection of goods and cargo by owners hampering logistics operations. This problem in addition to others has continued to threaten the conduct of logistic operations of the company for a number of years. It is on this basis that the researcher is interested in analyzing the effects of warehouse management on operational performance of clearing and forwarding companies in Rwanda taking a case of Gorrilla logistics at Airport. The study is examined the relationship between warehouse management and operational performance of clearing and forwarding companies in Rwanda with reference Gorrilla logistics.

\subsection{Literature review}

\subsection{Empirical literature}

Warehouse Management is uncommonly basic for prevalent execution of the company. In Macedonia, a think approximately was conducted by Natasha et al., (2017) to choose how coordination sharpens influence on companies' execution. The study utilized straight backslide examination appear. The comes around of the think approximately appeared a basic influence of stockroom organization on company's execution and recommended companies to be sharp on advancing the organization design of their dissemination center for more better achievement of viability in coordination works out.

Ohen and Ekaette (2018) in Nigeria analyzed the relationship between coordination operations and regulatory execution of Egg commerce individuals utilizing various backslide approach. Among the calculated operations they looked at included warehousing operations. The think approximately utilized fundamental data which was collected with offer assistance of studies. The comes around of the think approximately showed up that $76.7 \%$ of egg commerce individuals comes almost progress appeared that warehousing operations makes a contrast egg trade visionaries to preserve a key separate from perils of burglary and pilferage hence advance their benefits

Moses and Richard (2018) conducted a think almost in Mombasa area Kenya on coordination organization and organizational execution. The think almost centered on shipping companies in Mombasa Locale. One of the pointers of coordination organization was stockroom organization. The think approximately grasped multivariate backslide appear to choose the impacts of coordination organization on execution. The revelations of the think approximately revealed that conveyance center organization impacts organizational execution emphatically meaning that better stockroom organization may be a prerequisite for organizational execution. These revelations were in concurrence with the revelations of Mangala \& Moronge (2019) who carried the same consider but centering oil advancing companies in Kenya.

Vincent and Patrick (2018) analyzed the impacts of third party advantage providers along the supply chain on supply chain execution among creating companies in Rwanda. The think almost took a case of Bralirwa Company focusing at58 respondents. The revelations of the think almost revealed that warehousing organization which is among the third party advantage providers to a greater degree affected the execution of manufacturing companies in

\section{https://doi.org/10.53819/81018102t3017}


Rwanda. The think approximately endorsed true blue strategies to be gotten to overhaul capability in dissemination center organization so that in common execution of the company can make strides.

\subsection{Theoretical framework}

\subsubsection{Supply Chain Management Theory}

Supply chain Management theory was postulated by Jack Van (2004) stated that supply chain as a series of decision making processes and flows of materials and information that aims at achieving the ultimate goal of fulfilling customer satisfaction through providing customer requirements in the right quantity and quality and at the right time. Van further notes that this process takes place from one supply chain stage to another. Supply chain management on the other hand involves planning, coordination and control of all supply chain processes and activities with a goal of meeting consumer and other supply chain stakeholders' satisfaction at minimum supply chain costs. This theory can be related to a distributor who supplies several customers from a single source. The distributor incurs costs relate to transportation and warehousing. Transportation costs are composed of costs related to physical movement of goods from the warehouse to the customers. Efficient transport system is very crucial since it contributes much to time and place utility. Supply chain management theory supply chain contributes to this study on relationship between warehouse management and operational performance of Clearing and forwarding companies which forms the basis of this research and hence the supply chain management this theory is relevant to this study.

\subsection{Methodology}

This study is focused on clearing and forwarding companies and Gorrilla logistics located at airport is one of the Clearing and forwarding companies in Rwanda hence best suited this study. The research adopted a descriptive research design to answer research hypothesis. According to Kothari (2004), in a descriptive study design, objectives are fixed enabling the collection of relevant and satisfactory information to the problem of the study. All the 240 staff of Gorrilla logistics ltd formed the target population for this study comprising of senior level managers, middle level managers and subordinate staff. This study adopted the common Yamane's (1987). From the population of 240 staff members of Gorrilla logistics located at airport, a sample of 150 respondents was computed from Yamane's formulae below.

$n=\frac{N}{1+N^{*}(e) 2}$

where $\mathrm{n}$ is the sample size, $\mathrm{N}$ is the total population and e is the sampling error. By using the formula above when $\mathrm{e}=0.05, \mathrm{~N}=240$ then sample size $\mathrm{n}$ is 150 staff members. Therefore, we had 3 senior managers, 8 middle level managers and 139 subordinate staff.

Stratified sampling was used to select the sample size of 150 staff. The staff of Gorrilla logistics located at Airport is divided into three strata namely senior managers, middle level managers and subordinate staff. Simple random sampling is a probabilistic sampling technique whereby all population units have equal chance of selection (Mugenda \& 
Mugenda, 2008). The staff were selected randomly within each stratum. This data was collected using questionnaires.

The data was analyzed using both descriptive and inferential statistic. In descriptive statistic mean and standard deviation was used while in inferential statistic correlation and regression analysis was done. This involved computing means, standard deviations, frequencies and probability values which will be interpreted accordingly. The findings of this research were presented in form of tables and graphs. Pearson correlation coefficient was computed to reveal the degree of association between warehouse management and operational performance of Clearing and forwarding companies in Rwanda. The following multi-linear regression model applied in this research to analyze the relationship between the concerned variables.

$\mathrm{Y}=\beta_{0}+\beta_{1} \mathrm{X}_{1}+\varepsilon$ Where; Y- Operational performance; $\beta_{0^{-}}$Constant term; $\beta_{1},-$ Beta Coefficients; $\mathrm{X}_{1}$ - Warehouse management and $\varepsilon$ - Error term

\subsection{Key result and findings}

The researcher issued 150 questionnaires which was the sample size. These questionnaires were distributed to senior level managers, middle level managers and subordinate. Fortunately, the researcher managed to get back all the questionnaires that were issued out. This represented $100 \%$ questionnaire return rate.

Table 1: questionnaire return rate

\begin{tabular}{lrcr}
\hline & Frequency & Percent & Cumulative Percent \\
\hline returned & 150 & 100 & 100 \\
Not returned & 0 & 0 & 100.00 \\
Total issued & 150 & & \\
\hline
\end{tabular}




\subsection{Descriptive analysis of findings}

The researcher sought opinion of respondents on the effects on these warehouse management on operational performance. This was assessed on a Likert scale of measurement ranging from 1 to 5 represented strong agreements, 3 represented agreements, 2 represented neutral state, 1 represented disagreement and lastly 0 represented strong disagreement.

Table 2: warehouse management and operational performance

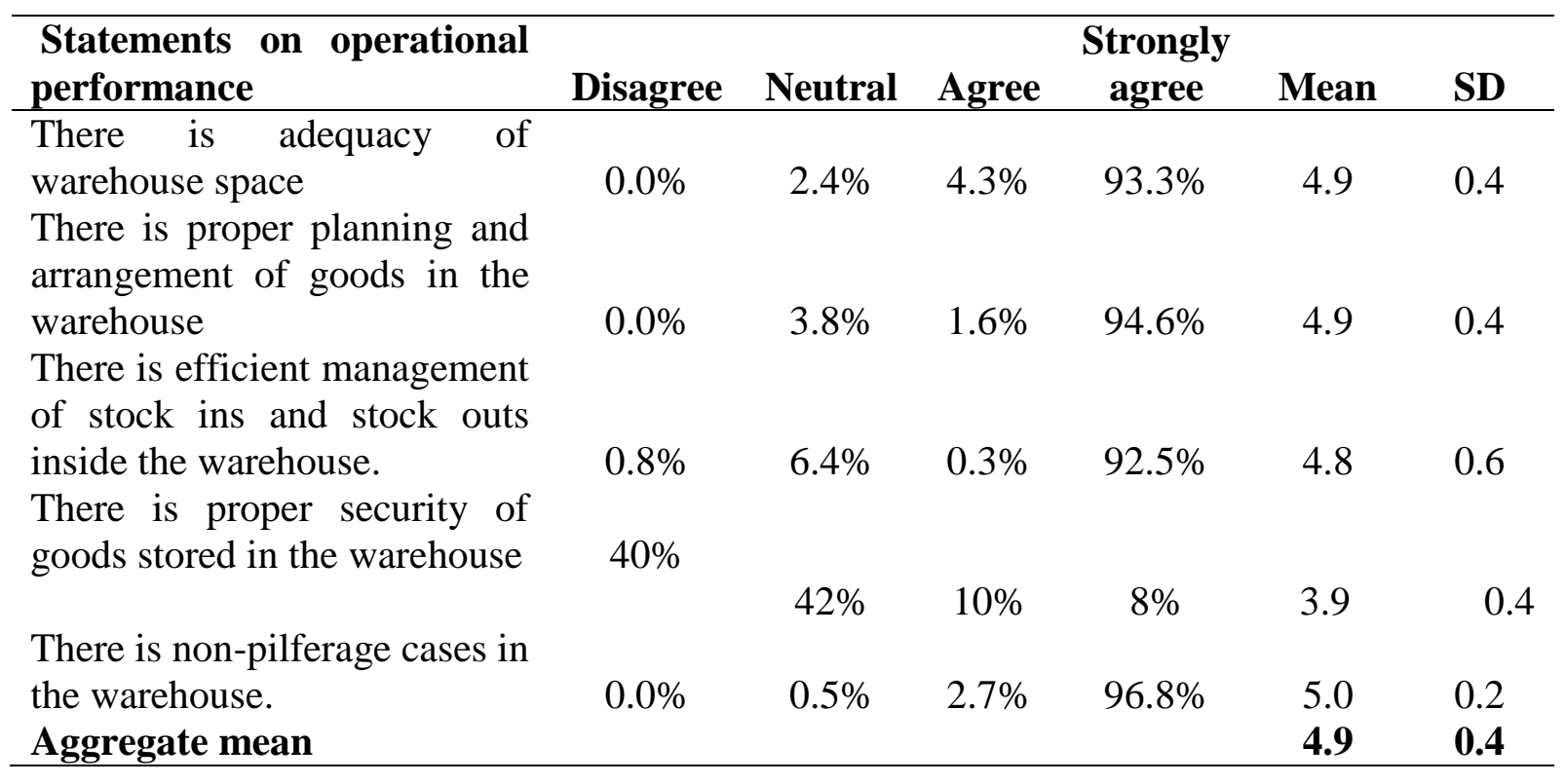

The results in Table 2 reveal that $2.4 \%$ of respondents neither agreed nor disagreed, 4.3\%agree while $93.3 \%$ strongly agreed with mean 4.9 and standard deviation of 0.4 that Gorrilla logistics ltd has adequacy of warehouse space. On statement that proper planning and arrangement of goods in the warehouse in Gorrilla logistics 3.8\% of respondents neither agreed nor disagreed , 1.6\%agree while 94.6\% strongly agreed that with mean 4.9 and standard deviation of 0.4 .On statement that efficient management of stock ins and stock outs inside the warehouse of Gorrilla logistics $40 \%$ of respondents disagreed $42 \%$ neither agreed nor disagreed , $10 \%$ agree while $8 \%$ strongly agreed that with mean 4.8 and standard deviation of 0.6 . on statement that there is proper security of goods stored in the warehouse. $8 \%$ of respondents disagreed $6.4 \%$ neither agreed nor disagreed, $0.3 \%$ agree while $92.5 \%$ strongly agreed that with mean 3.9 and standard deviation of 0.4 . Finally on statements that There is non-pilferage cases in the warehouse Gorrilla logistics none of respondents disagreed $0.5 \%$ neither agreed nor disagreed, $2.7 \%$ agree while $96.8 \%$ strongly agreed that with mean 5 and standard deviation of 0.2 . The overall average of 5 indicates that the majority of respondents agreed with most statements about effect of warehouse management on operational performance of clearing and forwarding of Gorrilla logistics ltd. This indicates that warehouse management affects operational performance of Gorrilla logistics. Additionally, the overall standard deviation of 0.2 implies that the data was distributed around the mean. This means that majority of the respondents' shared similar opinion in regard to statements on effect of warehouse management on operational performance of Gorrilla logistics ltd. 


\subsection{Inferential Statistics}

The analysis of the findings in this research constituted descriptive and inferential statistics. Correlation analysis is one of the inferential statistics that the study conducted. Correlation analysis involves determining the degree and direction of association between two variables. This study conducted correlation between the three logistic management techniques and operational performance.

\subsubsection{Correlation between warehouse management and operational performance}

This was assessed by computing the Pearson's correlation coefficient. From the findings the Pearson's correlation coefficient for warehouse management and operational performance was found to be 0.71 . The significance value was reported as 0.01 . This is an indication of a strong positive correlation between warehouse management and operational performance. The findings are summarized in the following table.

Table 3: Correlation between warehouse management and operational performance

\begin{tabular}{cccc}
\hline & & $\begin{array}{c}\text { Warehouse } \\
\text { management }\end{array}$ & Operational Performance \\
\hline $\begin{array}{c}\text { Warehouse } \\
\text { management }\end{array}$ & Pearsons Correlation & 1 & $.710^{* *}$ \\
Sig. (2-tailed) & $\mathrm{N}$ & .001 \\
$\begin{array}{c}\text { Operational } \\
\text { Performance }\end{array}$ & Pearsons Correlation & $.710^{* *}$ & 150 \\
& Sig. (2-tailed) & .001 & 1 \\
$\mathrm{~N}$ & 150 & 150 \\
\hline
\end{tabular}

Lastly the researcher conducted correlation analysis between transport management and operational performance. The Pearson's correlation coefficient was found to be 0.68 with a significance value of 0.01 . This is an indication that there is a strong positive significant relationship between transport management and operational performance. The model summary results, ANOVA results and coefficient results are presented in Table 4,5 and 6 respectively. 
Table 4: Model summary

\begin{tabular}{cccc}
\hline Model & R Square & Adjusted R Square & Std. Error of the Estimate \\
\hline 1 & .684 & .581 & .45895 \\
\hline
\end{tabular}

Table 5: ANOVA

\begin{tabular}{cccccc}
\hline \multicolumn{1}{c}{ Model } & Sum of Squares & Df & F & Sig. \\
\hline 1 & Regression & 43.565 & 3 & 90.501 & $.000^{\mathrm{a}}$ \\
& Residual & 21.453 & 95 & & \\
Total & 64.918 & 98 & & \\
\hline
\end{tabular}

b. Dependent Variable: operational

Performance

Table 6: Model Coefficients

Unstandardized Coefficients

\begin{tabular}{cccccc} 
& Model & B & Std. Error & t & Sig. \\
\hline 1 & .312 & .117 & .118 & .000 \\
$\begin{array}{c}\text { Warehouse } \\
\text { management }\end{array}$ & .194 & .068 & 1.786 & .012 \\
\hline
\end{tabular}

a. Dependent Variable: operational performance

From the model summary table, $\mathrm{R}$ squared value is 0.684 equivalent to $68.4 \%$. this is an indication that logistics management techniques captured by this study accounts for $68.4 \%$ of the variations in operations performance. in the ANOVA table, the calculated F statistics is 90.501 which is fairly large an indication that the multivariate regression model adopted in this study is appropriate. Lastly the coefficients table shows that the beta coefficients for constant term, information systems management, warehouse management and transport management are $0.312,0.253,0.194$ and 0.112 respectively. This implies keeping other factors constant, $1 \%$ change in warehouse management and transport management accounts for $19.4 \%$ proportionate change in operational performance respectively.

The null hypothesis was to $\mathrm{H}_{02}$ warehouse management has no significance effect the operational performance of Gorrilla logistics ltd. According to table 6 the results shows that Warehouse management had $\mathrm{p}=0.012>0.05$ hence we reject null hypothesis and conclude 
that findings reveal that there is not significance effect of warehouse management on operational performance of Gorrilla logistics ltd

Descriptive findings in this study did indicate that the overall average of 5 indicates that the majority of respondents agreed with most statements about effect of warehouse management on operational performance of clearing and forwarding of Gorrilla logistics ltd. This indicates that warehouse management affects operational performance of Gorrilla logistics. Additionally, the overall standard deviation of 0.2 implies that the data was distributed around the mean. This means that majority of the respondents' shared similar opinion in regard to statements on effect of warehouse management on operational performance of Gorrilla logistics ltd from the correlation analysis findings, the Pearson's correlation coefficient was found to be 0.71 which is positive and significant at 0.01 . Therefore, there is a strong positive relationship between warehouse management and operational performance from the regression findings, the beta coefficient of warehouse management correspondents to 0.194 . This implies that $1 \%$ positive change on warehouse management leads to $19.4 \%$ proportionate change in operational performance. These findings are similar to those of Natasha et al (2017), Moses \& Richard (2018) and Vincent \& Patrick (2018) in Macedonia, Kenya and Rwanda respectively who also found that warehouse management is key for achievement of operational performance.

Proper storage of goods in the warehouse is very important for performance of organization. proper management of the warehouse incorporates good arrangement of goods in the warehouse, security of the goods stored in the warehouse, non labelling of goods stored in the warehouse according to the sender and recipient details among others, this is necessary to avoid damage and pilferage of goods stored in the warehouse, easy retrieval of goods and cargo and avoiding overcrowding of goods in the warehouse which ultimately leads to positive effect on performance of operations. Pearson's correlation coefficient was found to be 0.71 which was positive and significant.

\subsection{Conclusion}

From finding it is clear that warehouse management has relationship on operational performance of clearing and forwarding of Gorrilla logistics . It can be concluded that proper storage of goods in the warehouse is very important for performance of organization. proper management of the warehouse incorporates good arrangement of goods in the warehouse, security of the goods stored in the warehouse, non-labelling of goods stored in the warehouse according to the sender and recipient details among others, this is necessary to avoid damage and pilferage of goods stored in the warehouse, easy retrieval of goods and cargo and avoiding overcrowding of goods in the warehouse which ultimately leads to positive effect on performance of operations

\subsection{Recommendations}

The study recommends that companies should consider enhancing warehouse management techniques. There should be proper arrangement of goods within the warehouse to maintain order and decency in addition to ensuring that easy retrieval of a client's cargo is possible. Security of cargo and goods should be enhanced all the time to avoid theft and loss of cargo and goods and in addition avoiding pilferage. In addition, companies should strive to expand their warehouse space to accommodate the increasing demand for warehouse services with

https://doi.org/10.53819/81018102t3017 
time. This will ease the pressure on the space available and hence smooth running of operations.

This study recommends that more research be done on the effect of other warehousing management not captured in this study on operational performance. Additionally, more research can be done on the effects of these three logistics management practices on financial performance of clearing and forwarding companies.

Lastly the study recommends that more research be done on effect of warehousing management on operational performance of other companies apart from clearing and forwarding companies so that the results can be compared.

\section{References}

An, H., Razzaq, A., Nawaz, A., Noman, S. M., \& Khan, S. A. R.. (2019). Impact of Logistics Management on Organizational Performance. Acase Study of Dangote Flour Mills PLC Nigeria. Journal of Sustainable Development in Africa, Vol 21.

Enock P. \& Namusonge A. (2017). The Effect of Transport Management on Organizational Performance Among Textile Manufacturing Firms in Kenya. International Journal of Academic Research in Business and Social Sciences, 7(11), 1032-1046. https://doi.org/10.6007/IJARBSS/v7-i11/3542

Fellows.O \& Liu. P (2008). Ethics in Construction Project Briefing. Journal of Science and Engineering thics, 10(2), 289-302. https://doi.org/10.1007/s11948-004-0025-5

Fugate, B. S., Mentzer, J. T., \& Stank, T. P. (2011). Logistics performance: efficiency, effectiveness, and differentiation. Journal of business logistics, 31(1), 43-62. https://doi.org/10.1002/j.2158-1592.2010.tb00127.x

Georgena J. \& Daniel. K. (2015). An Assessment of Effect of Logistics Management Practices on Operational Efficiency at Mumias Sugar Company, Kenya. International Journal of Economics, Commerce and Mnagement, 3(6), 1134-56.

Humphrey K. \& Robert.M, (2017). Effects of Logistics Activities on Performance of AgroProcessing Firms in Uasin Gishu Country, Kenya. IOSR Journal of Business and Management, 21-28.

Nyaberi, J. N., \& Mwangangi, P. (2014).Effects of Logistics Management Practices on organization Performance in Kenya. A Case of Rift Valley Bottlers in Uasin Gishu County. International Journal of Social Sciences and Entrepreneurship, 1(12), 458473.

Kaan A.(2015). The Fundamental Roles of Freight Forwarder in the Execution of International Logistics. Birmingham City University.

Kothari C.R. (2010). Research Methodology: Methods and Techniques. New Delhi, India: New Age International.

Liu P. \& Luo. M (2008). Effect of Logistics Capabilities on Performance in Manufacturing Firms. Hong kong: Human University of Technology China.

Moses K. \& Richard.F (2017). Effects of Logistics Management on the Performnace of Shipping Firms in Mombasa County . The Strategic Journal of Busines and Change Management, 821-839.

Mugenda O.M \& Mugenda A.G. (2008). Research Methods: Qualitative and Quantitative Approaches. Nairobi: African Centre for Technology Studies. 
Moore, B. R., Adams, T., Allain, V., Bell, J. D., Bigler, M., Bromhead, \&Natasha S. (2017). The Impact of Logistics Management Practices on company's Performance. International Journal of Academic Research in Accounting, Finance and Management science, 7(1),245-252. https://doi.org/10.6007/IJARAFMS/v7-i1/2649

Saunders M., Lewis, P., \& Thornhill, A. (2009). Research Methods for Business Students. Essex: Pearson Education Ltd.

Timna D. (2015). Impact of Logistics and Transportation Practices on Performance of Kenya Cooperative Creameries. University of Nairobi Repository. 